\title{
USE OF ABBREVIATIONS IN MEDICAL PRACTICE IN A UNIVERSITY HOSPITAL IN EGYPT
}

\author{
By \\ El tehewy M , EL Okda EL, Mohamed J and Essam N \\ Department of Community, Environmental and Occupational Medicine,
} Ain Shams University, Cairo, Egypt

\begin{abstract}
:
Background: Regardless of their convenience, medical abbreviations have been responsible for serious errors and deaths. Look-alike abbreviations or symbols, throughout the healthcare literature, are widespread examples of common errors. These problems involve numbers as well as letters. Objectives: To identify used abbreviations in medical records in surgical departments in El-demerdash hospital and to assess comprehension level of abbreviations written in medical records by medical and paramedical staff. Material and methods: A cross sectional study was done to review 400 medical records in surgical departments in El-demerdash hospital for identification of used abbreviations. Three hundred healthcare professionals in Eldemerdash hospital were inquired to identify the meaning of the top (5\%) frequently used abbreviations in a self-administered questionnaire. Results: More than 900 different abbreviations were identified in the studied sample. Most of them (56\%)were used in documenting history and physical examination followed by lab report (20.6\%). When medical dictionary was used to identify meaning of the most frequently used abbreviations (top $10 \%)$ only $(18.4 \%)$ of these abbreviations were identified. Meanings of abbreviations were obtained from five general surgery consultants. There were different abbreviations used for a single meaning and different meanings given to a single abbreviation. The factors that significantly affected the number of used abbreviations were length of stay, condition at discharge and department where the patient was staying. The most frequently used abbreviations (top5\%) were circulated in a questionnaire to assess the comprehension of these abbreviations among El-demerdash staff. In general, there was poor understanding of the abbreviations used in medical records. Only 3 out of 34 abbreviations were interpreted correctly by more than $(50 \%)$ of the study sample. Paramedical staff showed lower comprehension level than medical staff. Other factors
\end{abstract}


significantly affected comprehension level of abbreviations include years of experience and last certificate obtained by the participant. Conclusion: The study showed that medical abbreviations are widely used in a non-standardized way in medical records of Eldemerdash hospital. The majority of healthcare professionals had poor understanding of commonly used abbreviations which affects communication during patient care and may lead to medical errors.

\section{Introduction}

The term abbreviation is derived from the Latin brevis, or short. More specifically, it is a letter or a group of letters used to represent an entire word, (Kuhn, 2007). Medical abbreviations serve as a universal language to provide specific information and/or orders in a shortened format, (Jones, 2007). The use of abbreviations is very common throughout the medical world as a means of saving time and space whilst writing in the medical records. These abbreviations are usually not taught as a part of core curriculum in medical or nursing courses. Residents and trainee specialists learn them in the course of their day-today clinical work. With the development of specialties, each has produced a collection of commonly used abbreviations within its practice, (Parvaizet al., 2008)

Regardless of their convenience, medical abbreviations have been responsible for serious errors and deaths. Look-alike abbreviations or symbols, throughout the healthcare literature, are widespread examples of common errors. These problems involve numbers as well as letters. According to the Institute for Safe Medication Practices (ISMP) over 7,000 deaths per year may be attributed to medication errors. The use of abbreviation and medical notation makes a significant contribution to this statistic (Kuhn, 2007). Clinicians may misinterpret a letter or symbol and, because of this misinterpretation, administer a wrong medication or dose or give medication at the wrong time or with the wrong frequency.

The Joint Commission on Accreditation of Healthcare Organizations (JCAHO) has established a safety goal for 2004 related to the use of dangerous abbreviations, acronyms, and symbols. JCAHO recommends that facilities limit their use of certain abbreviations and has required facilities to stop using five specific sets of abbreviations as of Jan 1, 2004 (Beyea, 2004). The Safe Practices Steering Committee of the National Quality Forum (NQF) also recommends avoiding abbreviations and dose expressions deemed to be dangerous (Helen, 2008).

InEgypt, use of abbreviations in medical records has not been studied before. What 
are the common abbreviations in use in Egypt? And how does the staff comprehend it? The answer of these two questions will help the quality professionals to control the use of abbreviations in medical records, improve effectiveness of communication among health care givers and ensure patient safety.

\section{Aim of The Study}

- To identify used abbreviations in medical records in surgical departments in El-demerdash hospital

- To determine comprehension level of abbreviations written in medical records by different health care occupations

\section{Methodology}

A cross sectional study was conducted in general and special surgery departments of El-demerdash hospital. The study included both medical records and healthcare providers. The medical records of the patients admitted during a period of 3 months from April to June 2010 were found to be 8756 .Sample size was calculated using $\alpha$ equals 0.05 , confidence level $95 \%$ and was found to be 369. A $10 \%$ drop out, due to incompleteness of medical records was added so 400 medical records were examined for the used medical abbreviations. The first medical record was chosen randomly and then a systematic random sample was chosen every 20th medical record until reaching the required sample size according to the calculated skip interval. Each medical record was thoroughly reviewed using data extraction sheet to determine the abbreviations used in documenting data in the medical record.

The number of healthcare providers in general and specialized surgical departments was found to be 794 including physicians, nurses, technicians and pharmacists. The sample size was calculated using $\alpha$ equals 0.05 , confidence level $95 \%$ and was found to be 260 . Considering a $10 \%$ drop out, due to non-response so the sample size included 300 individuals. A proportionate stratified random sample was taken, where the size of the sample from each stratum was proportionate to the size of that stratum relative to the size of sampled population. To test understanding of abbreviations by healthcare providers a self-administered questionnaire was prepared and circulated. The questionnaire included inquiries about personal data and a list including $5 \%$ of the most frequently used abbreviations, excluding abbreviations used in lab report as they are all standardized. They were asked to write what abbreviations stood for if they knew in any language and then they were compared to the answers obtained 
from five general surgery consultants and checked if they were right, wrong or the responder didn't know the answer. The level of comprehensions was calculated according to the following key; high comprehension level means right answers for $>75 \%$ of the abbreviations, moderate comprehension level means right answers for 50 to $75 \%$ of the abbreviations and low comprehension level means right answers for $<50 \%$ of the abbreviations.

Time frame of the study: started at April 2012 till January 2013

\section{Ethical Considerations:}

Research conduction approval was obtained by Ain-Shams University Ethical Committee. Administrative approval was obtained and confidentiality of data was considered.

\section{Results}

Table (1) shows that 938 different abbreviations have been identified in 400 medical records and that half of them were used in documenting history and physical examination.

The abbreviations used in writing laboratory reports were excluded as they are universal abbreviations and thus the number of abbreviations studied in depth was (745). Table (2) shows that the most frequently observed abbreviations used in the history and physical examination were «abd» and «ant», and that used in diagnosis was «DM». The Arabic letter “i»was the most frequent abbreviation used in prescribing medication, while «CT» was In $\mathrm{x}$-ray reports and «G.A» in anesthesia and procedure reports.

Table (3) shows a statistically significant model $(\mathrm{F}=23.05, \mathrm{p}<0.01)$ with coefficient of determination equals $32 \%$. The department, condition at discharge and length of stay were the determinants of overall abbreviation count in medical record which was used as the dependent variable in this model. The largest abbreviation count was in favor of orthopedics department and for a patient who was referred and increase in length of stay. Figure (1) shows a statistically significant positive correlation between length of stay and total abbreviation count in medical record with Pearson correlation coefficient +0.36 and $\mathrm{P}$ value $<0.01$.

A questionnaire including the most frequently used abbreviations (top 5\%) was prepared and circulated among 313 of healthcare providers of Eldemerdash hospital. The mean age of the participants was $30 \pm 7$ years ranging from 18 to 56 years old, $56 \%$ of them were males and the majority of them were nurses and physicians with work experience of $<5$ years, (table 4). 
The percentage of healthcare providers who don>t know the meaning of the top $5 \%$ of used abbreviations varied between $39.6 \%$ up to $97.8 \%$.In general,67.7\%, $24.9 \%$ and $7.3 \%$ of the study sample have low, moderate, and high comprehension level for used abbreviation, (table 5)

Studying factors affecting comprehension level of abbreviations shows no significant difference between $\quad(p<0.05)$. age groups, while healthcare providers with experiences of less than 5 years had better comprehension level of abbreviations. Table (5) shows also that physicians in general and pharmacist had higher level of comprehension compared to nurses and technicians, $(\mathrm{p}<0.05)$. On the other hand master and doctor degrees had higher level of comprehension compared to other certificates (28.6\% and $20 \%$ respectively),

Table (1): Classification of identified abbreviations according to their use.

\begin{tabular}{|l|c|c|}
\hline Use of abbreviation & $\begin{array}{c}\text { Number of } \\
\text { abbreviations }\end{array}$ & Percent \\
\hline History and physical examination & 523 & $55.8 \%$ \\
\hline Laboratory report & 193 & $20.6 \%$ \\
\hline Diagnosis & 56 & $6 \%$ \\
\hline Medication orders & 47 & $5 \%$ \\
\hline Procedures & 37 & $3.9 \%$ \\
\hline Nursing and administration & 20 & $2.1 \%$ \\
\hline X-ray report & 11 & $1.2 \%$ \\
\hline Others & 51 & $5.4 \%$ \\
\hline Total & 938 & 100 \\
\hline
\end{tabular}


Table (2)Distribution of most frequently observed abbreviation (top 5\%) according to their use (excluding lab report)

\begin{tabular}{|c|c|c|c|c|c|c|}
\hline Use & Abbrev. & Freq. & $\%$ & Abbrev. & Freq. & $\%$ \\
\hline \multirow{13}{*}{$\begin{array}{l}\text { History and Physical } \\
\text { Examination }\end{array}$} & abd & 338 & 84.5 & ICU & 92 & 23 \\
\hline & ant & 175 & 43.75 & lt & 72 & 18 \\
\hline & bl. & 163 & 40.75 & $\mathrm{~L}$ & 87 & 21.75 \\
\hline & bl.p & 158 & 39.5 & lat & 80 & 20 \\
\hline & bl.pr & 155 & 38.75 & LLs & 78 & 19.5 \\
\hline & BP & 148 & 37 & M & 56 & 14 \\
\hline & BPM & 121 & 30.25 & $\mathrm{MCV}$ & 54 & 13.5 \\
\hline & exam & 109 & 27.25 & med & 50 & 12.5 \\
\hline & $\mathrm{FC}$ & 103 & 25.75 & $\mathrm{MmHg}$ & 43 & 10.75 \\
\hline & $\mathrm{H}$ & 100 & 25 & MP & 41 & 10.25 \\
\hline & $\mathrm{HB}$ & 98 & 24.5 & MS & 41 & 10.25 \\
\hline & Hrs & 96 & 24 & $\mathrm{~N}$ & 38 & 9.5 \\
\hline & $\mathrm{Ht}$ & 95 & 23.75 & NAD & 37 & 9.25 \\
\hline \multirow[t]{2}{*}{ Diagnosis } & D.M & 111 & 27.75 & fr & 24 & 6 \\
\hline & $\mathrm{Htn}$ & 94 & 23.5 & bilat & 19 & 4.75 \\
\hline \multirow{2}{*}{$\begin{array}{l}\text { Medication by Physicians and } \\
\text { Nurses }\end{array}$} & f* & 294 & 73.5 & ) & 224 & 56 \\
\hline & (جم & 279 & 69.75 & *م.ن.ض.ح & 210 & 52.5 \\
\hline \multirow[t]{2}{*}{ X Ray } & $\mathrm{CT}$ & 103 & 25.75 & *أشعة أخ & 54 & 13.5 \\
\hline & $\mathrm{U} / \mathrm{S}$ & 67 & 16.75 & *أشعة ج & 47 & 11.75 \\
\hline Procedures & G.A & 46 & 11.5 & $\mathrm{~S} \& \mathrm{~T}$ & 32 & 8 \\
\hline Others & é & 163 & 40.75 & $\mathrm{~cm}$ & 43 & 10.75 \\
\hline
\end{tabular}

*Abbreviations in Arabic Language 
Table (3): Linear regression for determinants of abbreviation count in medical records

\begin{tabular}{|l|c|c|c|c|c|}
\hline & \multicolumn{2}{|c|}{$\begin{array}{c}\text { Unstandardized } \\
\text { Coefficients }\end{array}$} & $\begin{array}{c}\text { Standardized } \\
\text { Coefficients }\end{array}$ & t & \multirow{2}{*}{ Sig. } \\
\cline { 2 - 5 } Constant & B & SD Error & Beta & & \\
\hline Department & 6.695 & 1.618 & & & \\
\hline Ear, nose and throat & -3.622 & 1.859 & -0.107 & -1.949 & 0.052 \\
\hline General surgery & 5.413 & 1.721 & 0.174 & 3.146 & 0.002 \\
\hline Neurosurgery & 5.710 & 1.954 & 0.176 & 2.922 & 0.004 \\
\hline Orthopedics & 6.849 & 1.965 & 0.216 & 3.486 & 0.001 \\
\hline Urosurgery & -.365 & 1.668 & -0.012 & -.219 & 0.827 \\
\hline Condition at discharge & & & & & \\
\hline Improved & 8.588 & 1.603 & 0.350 & 5.356 & 0.000 \\
\hline Referred & 11.065 & 1.762 & 0.365 & 6.280 & 0.000 \\
\hline Length Stay & .283 & .041 & 0.306 & 6.949 & 0.000 \\
\hline
\end{tabular}


Table (4): Socio-demographic data of the studied sample of healthcare providers (313)

\begin{tabular}{|l|c|c|}
\hline & Frequency & Percent (\%) \\
\hline Gender & & \\
\hline Female & 176 & 56.2 \\
\hline Occupation & 137 & 43.8 \\
\hline Nurse & & 51.8 \\
\hline Resident & 162 & 31.9 \\
\hline Technician & 100 & 9.9 \\
\hline Pharmacist & 31 & 3.2 \\
\hline Unit Director & 10 & 3.2 \\
\hline Certificate & 10 & 35.6 \\
\hline Nursing / technical school diploma & 174 & 39 \\
\hline Bachelor Degree & 122 & 24.6 \\
\hline Master Degree & 7 & 3.2 \\
\hline MD Degree & 10 & \\
\hline Experience (in years) & & 33.8 \\
\hline$<5$ & 137 & \\
\hline $5-10$ & & \\
\hline$>10$ & & \\
\hline
\end{tabular}


Table (5): Relation between personal data of the studied sample of healthcare providers and comprehension level for abbreviation

\begin{tabular}{|c|c|c|c|c|c|c|}
\hline \multirow{2}{*}{\multicolumn{2}{|c|}{ Low }} & \multicolumn{3}{|c|}{ Comprehension Level } & \multirow{3}{*}{$\begin{array}{c}\text { Total } \\
176 \\
(100 \%)\end{array}$} & \multirow{3}{*}{$\begin{array}{c}\text { P value } \\
>0.05\end{array}$} \\
\hline & & \multirow{2}{*}{\begin{tabular}{|c|} 
Moderate \\
110 \\
$(62.5 \%)$
\end{tabular}} & \multirow{2}{*}{$\begin{array}{c}\text { High } \\
51 \\
(29 \%)\end{array}$} & \multirow[b]{2}{*}{$\begin{array}{c}15 \\
(8.5 \%) \\
\end{array}$} & & \\
\hline \multirow{2}{*}{ Gender } & Male & & & & & \\
\hline & Female & $\begin{array}{c}102 \\
(74.5 \%)\end{array}$ & $\begin{array}{c}27 \\
(19.7 \%) \\
\end{array}$ & $\begin{array}{c}8 \\
(5.8 \%) \\
\end{array}$ & $\begin{array}{c}137 \\
(100 \%)\end{array}$ & \\
\hline \multicolumn{2}{|l|}{ Total } & $\begin{array}{c}212 \\
(67.7 \%) \\
\end{array}$ & $\begin{array}{c}78 \\
(24.9 \%) \\
\end{array}$ & $\begin{array}{c}23 \\
(7.3 \%) \\
\end{array}$ & $\begin{array}{c}313 \\
(100 \%) \\
\end{array}$ & \\
\hline \multirow{3}{*}{$\begin{array}{l}\text { Experience (in } \\
\text { years) }\end{array}$} & $<5$ & $\begin{array}{c}57 \\
(41.6 \%) \\
\end{array}$ & $\begin{array}{c}61 \\
(44.5 \%) \\
\end{array}$ & $\begin{array}{c}19 \\
(13.9 \%) \\
\end{array}$ & $\begin{array}{c}137 \\
(100 \%) \\
\end{array}$ & $<0.05$ \\
\hline & $5-10$ & $\begin{array}{c}94 \\
(94.9 \%) \\
\end{array}$ & $\begin{array}{c}4 \\
(4 \%) \\
\end{array}$ & $\begin{array}{c}1 \\
(1 \%) \\
\end{array}$ & $\begin{array}{c}99 \\
(100 \%) \\
\end{array}$ & \\
\hline & $>10$ & $\begin{array}{c}61 \\
(79.2 \%)\end{array}$ & $\begin{array}{c}13 \\
(16.9 \%)\end{array}$ & $\begin{array}{c}3 \\
(3.9 \%)\end{array}$ & $\begin{array}{c}77 \\
(100 \%)\end{array}$ & \\
\hline \multicolumn{2}{|l|}{ Total } & $\begin{array}{c}212 \\
(67.7 \%)\end{array}$ & $\begin{array}{c}78 \\
(24.9 \%)\end{array}$ & $\begin{array}{c}23 \\
(7.3 \%)\end{array}$ & $\begin{array}{c}313 \\
(100 \%)\end{array}$ & \\
\hline
\end{tabular}

\begin{tabular}{|c|c|c|c|c|c|c|}
\hline \multirow{5}{*}{ Occupation } & Nurse & $\begin{array}{c}153 \\
(94.4 \%)\end{array}$ & $\begin{array}{c}9 \\
(5.6 \%)\end{array}$ & $\begin{array}{c}0 \\
(0 \%)\end{array}$ & $\begin{array}{c}162 \\
(100 \%)\end{array}$ & $<0.05$ \\
\hline & Pharmacist & $\begin{array}{c}2 \\
(20 \%) \\
\end{array}$ & $\begin{array}{c}5 \\
(50 \%) \\
\end{array}$ & $\begin{array}{c}3 \\
(30 \%) \\
\end{array}$ & $\begin{array}{c}10 \\
(100 \%) \\
\end{array}$ & \\
\hline & Technician & $\begin{array}{c}30 \\
(96.8 \%) \\
\end{array}$ & $\begin{array}{c}1 \\
(3.2 \%) \\
\end{array}$ & $\begin{array}{c}0 \\
(0 \%) \\
\end{array}$ & $\begin{array}{c}31 \\
(100 \%) \\
\end{array}$ & \\
\hline & Resident & $\begin{array}{c}27 \\
(27 \%) \\
\end{array}$ & $\begin{array}{c}55 \\
(55 \%) \\
\end{array}$ & $\begin{array}{c}18 \\
(18 \%) \\
\end{array}$ & $\begin{array}{c}100 \\
(100 \%)\end{array}$ & \\
\hline & Unit Director & $\begin{array}{c}0 \\
(0 \%) \\
\end{array}$ & $\begin{array}{c}8 \\
(80 \%) \\
\end{array}$ & $\begin{array}{c}2 \\
(20 \%) \\
\end{array}$ & $\begin{array}{c}10 \\
(100 \%) \\
\end{array}$ & \\
\hline \multicolumn{2}{|l|}{ Total } & $\begin{array}{c}212 \\
(67.7 \%) \\
\end{array}$ & $\begin{array}{c}78 \\
(24.9 \%) \\
\end{array}$ & $\begin{array}{c}23 \\
(7.3 \%) \\
\end{array}$ & $\begin{array}{c}313 \\
(100 \%) \\
\end{array}$ & \\
\hline \multirow{4}{*}{ Certificate } & Bachelor degree & $\begin{array}{c}40 \\
(32.8 \%)\end{array}$ & $\begin{array}{c}63 \\
(51.6 \%)\end{array}$ & $\begin{array}{c}0 \\
(0 \%)\end{array}$ & $\begin{array}{c}122 \\
(100 \%)\end{array}$ & $<0.05$ \\
\hline & $\begin{array}{l}\text { Nursing / technical } \\
\text { school Diploma }\end{array}$ & $\begin{array}{c}172 \\
(98.9 \%) \\
\end{array}$ & $\begin{array}{c}2 \\
(1.1 \%) \\
\end{array}$ & $\begin{array}{c}0 \\
(0 \%)\end{array}$ & $\begin{array}{c}174 \\
(100 \%) \\
\end{array}$ & \\
\hline & Master Degree & $\begin{array}{c}0 \\
(0 \%) \\
\end{array}$ & $\begin{array}{c}5 \\
(71.4 \%) \\
\end{array}$ & $\begin{array}{c}2 \\
(28.6 \%) \\
\end{array}$ & $\begin{array}{c}7 \\
(100 \%)\end{array}$ & \\
\hline & MD Degree & $\begin{array}{c}0 \\
(0 \%)\end{array}$ & $\begin{array}{c}8 \\
(80 \%)\end{array}$ & $\begin{array}{c}2 \\
(20 \%)\end{array}$ & $\begin{array}{c}10 \\
(100 \%)\end{array}$ & \\
\hline \multicolumn{2}{|l|}{ Total } & $\begin{array}{c}212 \\
(67.7 \%) \\
\end{array}$ & $\begin{array}{c}78 \\
(24.9 \%) \\
\end{array}$ & $\begin{array}{c}23 \\
(7.3 \%)\end{array}$ & $\begin{array}{c}313 \\
(100 \%) \\
\end{array}$ & \\
\hline
\end{tabular}


Figure (1): A scatter plot of total abbreviation count in medical record versus length of stay of patient in days

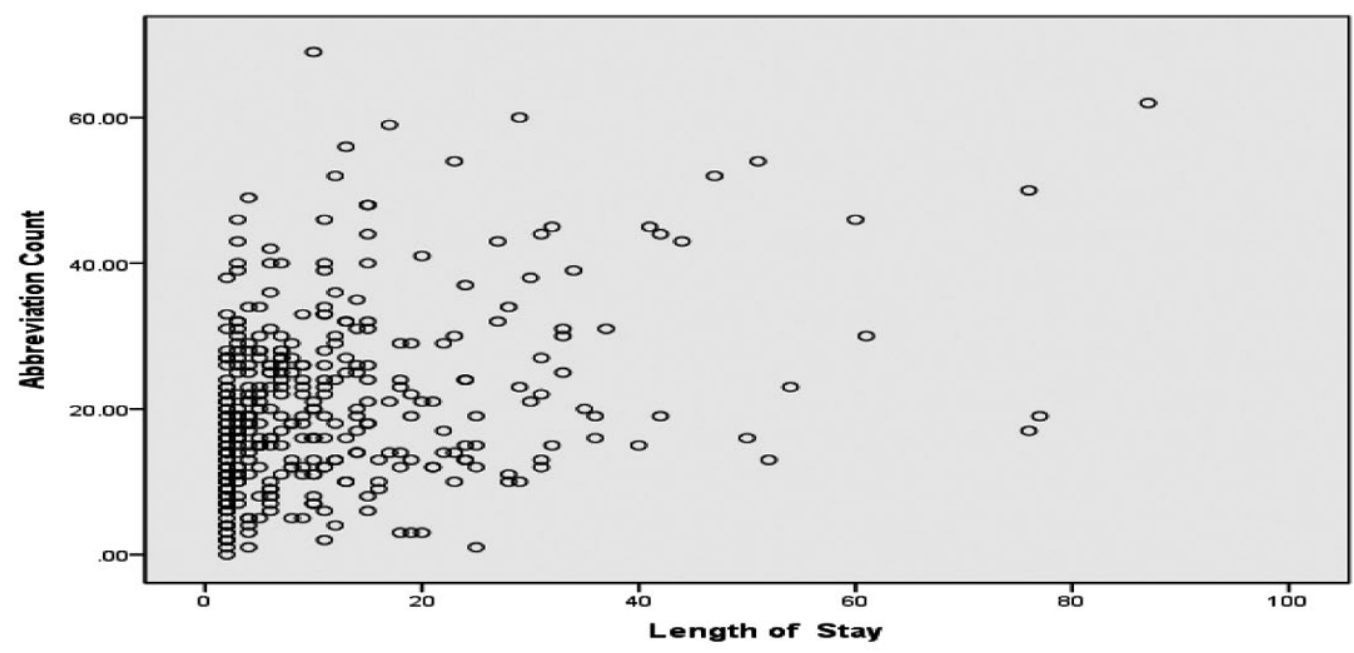

Correlation coefficient +0.36 and $\mathrm{P}$ value $<0.05$.

\section{Discussion}

Eldemerdash hospital is one of the four hospitals of Ain Shams University. It is 600 -bed capacity and specialized in surgery. The aim of this study was to identify the used abbreviations in medical records of general and specialized surgical departments in Eldemerdash hospital then assess comprehension level of abbreviations written in medical records by medical and paramedical staff working in the same hospital. A sample of 400 medical records of the patients admitted to Eldemerdash hospital during a period of 3 months from
April to June 2012 was reviewed for the use of abbreviations.

More than 900 different abbreviations have been identified, most of them used in documenting history and physical examination (55.8\%) and lab report (20.6\%). This is a large number if compared with the results of a study done by Sheppard et al. (2008) to identify abbreviations in a sample of 2286 pediatric notes and handover sheets and recognized 221 abbreviations.

Out of 47 abbreviations used in documenting medication orders and 
administration; there were 39 Arabic abbreviations written by physicians and nurses. This can be explained as most of nurses are holding nursing school diploma with little practices in English language; thus physicians prefer to write medication orders in Arabic and nurses also document medication administration in Arabic.

The mean number of used abbreviations per medical record was 19.67 and the largest number was observed in orthopedics department with a mean of 25 and the least was plastic surgery with a mean of 14 different abbreviations per medical record.

A statistically significant positive correlation was found between the total abbreviation count in medical record and length of stay with correlation coefficient of 0.36 ( $\mathrm{P}$ value $<0.01)$. Also, the total abbreviation count in each medical record was affected by condition at discharge being significantly more in referred cases, ( $\mathrm{P}$ value $<0.01)$. These findings were also supported by the results of the linear regression analysis that performed to determine determinants of abbreviation count in medical records. The study of Carroll et al. (2003) explained the relationship between use of abbreviations and length of stay as they found that misinterpretation of abbreviations leading to documentation error resulted in longer hospital stay.
The most frequent abbreviations used in the history and physical examination were «abd» (abdomen) and «ant» (anterior), in diagnosis was «D.M» (Diabetes Mellitus), in $\mathrm{x}$-ray was «CT» (Computed Topography) and in anesthesia and procedures' reports was "G.A" (General Anesthesia). The most frequent abbreviation written by physicians and nurses for prescribing and administering medication was the Arabic letter that means ampoule. Among the most frequent other abbreviations used was "é" (with).

When dictionary was used to identify the meaning of the top $10 \%$ only 14 abbreviations out of $75(18.4 \%)$ were found. Sheppard et al. (2008) compared 221 abbreviations used in pediatrics with the TID and Mosby's Medical Dictionary and recognized only $14 \%$ and $20 \%$ respectively.

In the current study five general surgery consultants were asked to identify the meaning of the top 5\% list of abbreviations as "bl" standing for blood, "O/E" for on examination, "htn" for hypertension. Sometimes more than one abbreviation was used to refer for the same meaning as bl.p, bl.pr, BP which all referred to blood pressure. Some abbreviations were either not identified by consultants as $\mathrm{B}$ and $\mathrm{M}$ or they had more than one meaning as $\mathrm{L}$ which can mean low, lower and also left, 
MS which can mean mitral stenosis or multiple sclerosis and also, $\mathrm{N}$ which can mean normal or nerve. Similar findings were reported in other studies, (Akunjee et al., 2007) and Sheppard et al. (2008). This uncontrolled use and misinterpretation of abbreviations may result in poorer outcome. Bateman et al. (1999) found that 11.4 per cent of the drug errors may be due to the use of abbreviations and Al-Jeraisy et al. (2011) identified $17 \%$ incorrect abbreviations in medication orders in pediatric critical care units.

To achieve the second objective of this study; the most frequently used 5\% abbreviations were selected and a questionnaire including 34 abbreviation were circulated among 313 of staff members of Eldemerdash hospital.

The abbreviations mostly recognized by the studied sample were in Arabic language

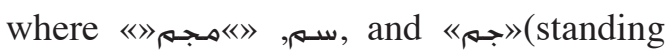
for $\mathrm{mgm}$, gm, and $\mathrm{cm}$ ) were identified by $>50 \%$ of participants. The most commonly undefined abbreviations were «VS» which was identified only by $(1 \%)$ of the participants as well as «TPP» and «OTPP» which were identified by (2\%).

When comprehension level of abbreviations was compared among different occupation categories it was found that no single abbreviation had been recognized by $(50 \%)$ or more of nurses though some of these abbreviations were in Arabic and were used by nurses themselves. It seems that some nurses prefer to answer by do not know to avoid possibility of writing the wrong meaning and even if this assumption is true it indicates that they were not sure of the meaning of abbreviations. On the other hand; 22 of 34 abbreviations in the questionnaire were recognized by more than $(50 \%)$ of residents and there was a statistical significant relationship between comprehension of abbreviations and occupation (P value <0.01).

Similar results were found in a crosssectional study on the use of abbreviations in randomly selected general surgery inpatient medical records. The overall correct response $(43 \%)$, indicating a poor understanding of abbreviations by the majority of healthcare professionals doctors scored the highest with (57\%) correct responses in comparison nurses $(30 \%)$, dieticians and medical secretaries (20\%), (Sinha et al. 2011).

Our study showed a significant relationship between specialty and comprehension level of abbreviations with a $\mathrm{P}$ value $<0.01$.Comprehension level was mostly better in general surgery if compared to combined results of special surgeries. It seems that healthcare providers working in 
certain specialty are not oriented with all abbreviation used by other specialties.

Many studies investigated this issue and their results supported this assumption. In one study healthcare professionals from clinical departments other than pediatrics were asked to blindly interpret the abbreviations from pediatric medical records and none was able to interpret all correctly. The percentage of correct answers for non-pediatric clinicians varied from $31 \%$ to $63 \%$ in comparison to $56 \%$ to $94 \%$ for the pediatric team, (Sheppard et al. 2008). Another studies found that general practitioners' had a general lack of understanding of common ophthalmological acronyms, with 63\% of the total responses to the questionnaire being incorrect, (Akunjee et al. 2007). Also Parvaiz (2008) studied comprehension of abbreviations in medical records for orthopedic patients by different healthcare professionals. Orthopedic surgeons had the highest right answer scoring group. DasPurkayastha et al. (2004) found that 6 of 13 commonly used abbreviations in ENT were unclear to more than $90 \%$ of junior doctors from other specialties

The study showed also a significant relationship between experience (in years) and comprehension level of abbreviations with a $\mathrm{P}$ value $<0.01$. Participants with less than 5 years of experience had better levels of comprehension than the other two groups of more than 10 years of experience and form 5-10 years and the last group showed the worst level. This could be explained as quality of health care training and orientation was focused upon during the last 5 years in El dmerdash hospital through different programs. Some abbreviation lists were available after these programs this issue may improve the knowledge and raise the attention of the junior staff regarding that issue slightly than the others in addition to more contact chances with file than senior staff. On the other hand senior staff had less contact with the medical file in comparison to the junior and this may explain the difficulty to understand majority of abbreviations correctly.

The relationship between last certificate obtained by responder and comprehension level was significant with a $\mathrm{P}$ value $<0.01$. Majority of responders (81\%) with low comprehension level were those who obtained nursing/technical school diploma. This issue could be explained by difficulty of understanding especially English abbreviations due to language barrier of this group of staff.

In conclusion; abbreviations are widely used in non-standardized way in 
El-demerdash hospital and the majority of healthcare professionals have a poor knowledge of commonlyused abbreviations. Use of unambiguous and approved list of abbreviations is recommended in order to ensure good communication in patient care.

\section{References}

1. Al-Jeraisy $\mathrm{M}$, Alanazi $\mathrm{M}$ and Abolfotouh $\mathrm{M}$ (2011): Medication prescribing errors in a pediatric inpatient tertiary care setting in Saudi Arabia. Biomed central research notes ; 4:294.

2. Akunjee M, Ali N and Ahfat F (2007): The use of abbreviations in ophthalmologic correspondence with general practitioners. Quality in primary care; $15: 145-150$

3. Bateman N, Carney A and Gibben K (1999): An audit of the quality of operation notes in an otolaryngology unit. Journal of royal college of surgeons of Edinburgh; 44: 94-95.

4. Beyea $S$ (2004): Best practices for abbreviations use-Patient Safety First. AORN journal; 79(3):641-642.

5. Carroll A, Tarczy-Hornoch P, O'Reilly E and Christakis D (2003): Resident Documentation Discrepancies in a Neonatal Intensive Care Unit. Pediatrics; 111( 5): 976 -980 .

6. Das-Purkayastha P, McLeod K and Canter R (2004): Specialist medical abbreviations as a foreign language. Journal of the royal society of medicine; 97: 456-457.

7. Helen MF (2008): Do-Not-Use Abbreviations: Toolkit for Implementing National Patient Safety Goal 2B. Joint Commission Resources, chapter 1, p.4-5.
8. Institute for safe medication practices (2001): Please don't sleep through this wake-up call. ISMP medication safety alert. Available at: http://www.ismp.org/Newsletters/acutecare/ articles/20010502.asp Date of access: 26/6/2011.

9. Jones BD (2007):Comprehensive medical terminology. Third edition: Thomson Delmar learning, chapter 22, p.918

10. Kuhn IF (2007): Abbreviations and acronyms in healthcare: when shorter isn't sweeter: the patient safety issue in healthcare. Pediatric nursing; 33(5): 392-398.

11. Parvaiz MA, Subramanian A and Kendall NS (2008): The use of abbreviations in medical records in a multidisciplinary world- an imminent disaster. Communication \& medicine; 5(1): 25-34.

12. Sheppard J, Weidner L, Zakai S, FountainPolley S and Williams J (2008): Ambiguous abbreviations: an audit of abbreviations in pediatric note keeping

13. Sinha S, Mcdermott F, Srinivas G and Houghton P (2011): Use of abbreviations by healthcare professionals: what is the way forward? Postgraduate medical journal; 87(1029): 450452.

14. The Joint Commission on Accreditation of Health Organizations (2006): Implementation Tips for Eliminating Dangerous Abbreviations. Available at: D:I Medical abbreviations Implementation Tips for Eliminating Dangerous Abbreviations Joint Commission.mht. Date of access 24-7-2011. . Archives of disease in childhood; 93: 204-206. 